\title{
Iodolopyrazolium Salts - Synthesis, Derivatizations and Applications
}

Andreas Boelke ${ }^{[a]}$, Thomas J. Kuczmera ${ }^{[a]}$, Lucien D. Caspers ${ }^{[a]}$, Enno Lork $^{[b]}$ and Boris J. Nachtsheim*[a]

Address:

[a]Institute for Organic and Analytical Chemistry, University of Bremen, 28359 Bremen, Germany

${ }^{[b]}$ Institute for Inorganic Chemistry and Crystallography, University of Bremen, 28359 Bremen, Germany

Prof. Dr. Boris J. Nachtsheim, nachtsheim@uni-bremen.de
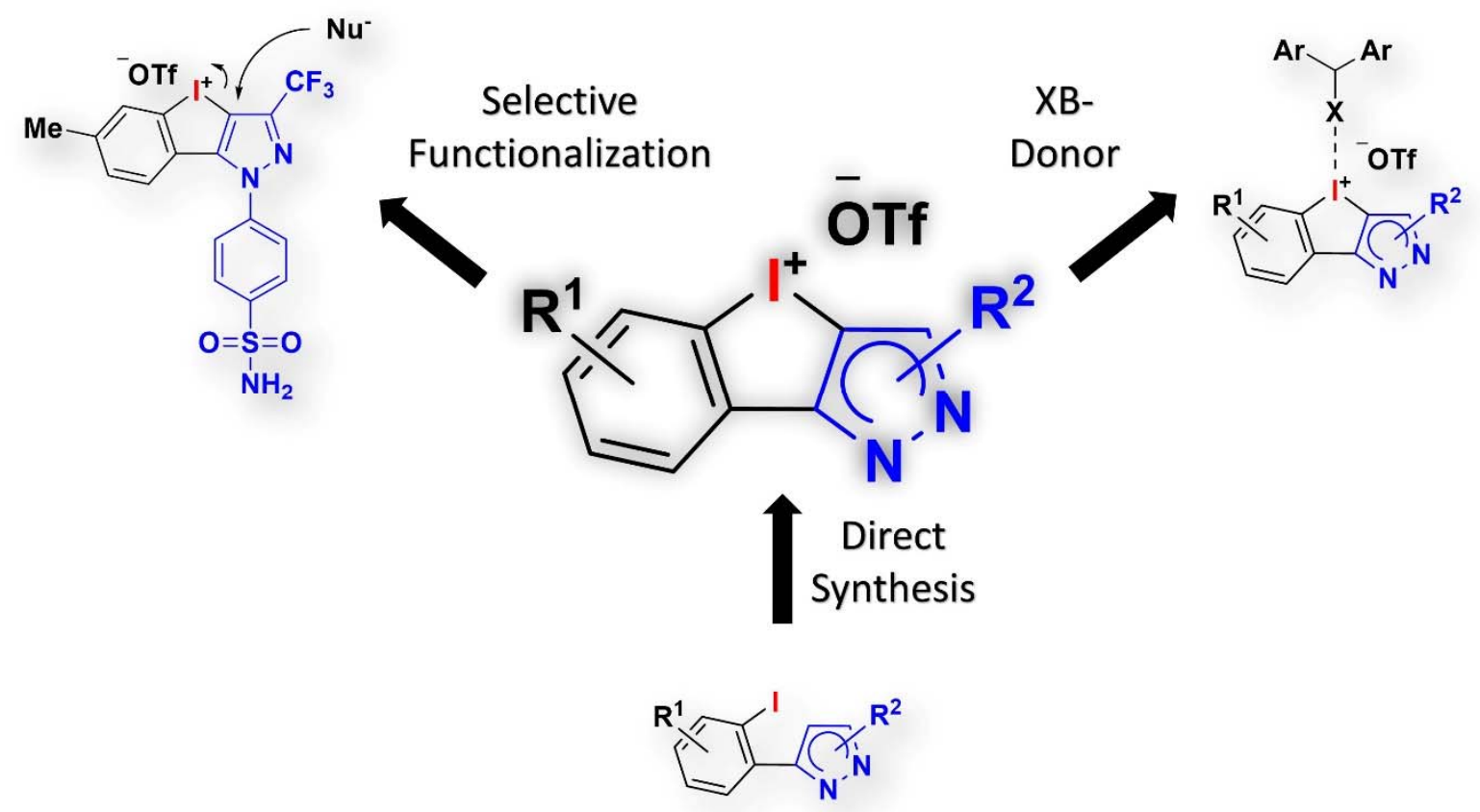


\section{Abstract}

The synthesis of iodolopyrazolium salts via an oxidative cyclization of 3-(2-iodophenyl)$1 \mathrm{H}$-pyrazoles is described. The reaction is characterized by a broad substrate scope and various applications of these novel cyclic iodolium salts acting as useful synthetic intermediates are demonstrated, in particular in site-selective ring-openings. This was finally applied to generate derivatives of the anti-inflammatory drug celecoxib. Their application as highly active halogen bonding donors is shown as well.

\section{Keywords}

hypervalent iodine $\cdot$ iodolium $\cdot \mathrm{N}$-heterocycles $\cdot$ oxidative cyclization $\cdot$ tricyclic pyrazoles

\section{Introduction}

Pyrazoles are found in numerous small molecules which exhibit a wide range of biological activities. Because of that the synthesis of complex structures bearing a pyrazole ring is of great interest in academic research and for the chemical-, pharmaceutical- and agricultural industry. ${ }^{[1-3]}$ Most prominent examples of pharmaceuticals substituted by pyrazoles are the highly selective COX-2 inhibitor Celecoxib, ${ }^{[4]}$ the anti-psychotic CDPPB ${ }^{[5]}$ or the anorectic anti-obesity drug Rimonabant ${ }^{[6]}$ (Figure 1, a). Analgesic and anti-inflammatory activity was ascertained for the natural product Whitasomnine, whereas Pyrazofurin exhibits promising antiviral and antitumor properties. ${ }^{[7,8]}$ Fused tricyclic pyrazole derivatives have been intensively investigated structural motifs in a wide range of medicinal studies as well. ${ }^{\left[{ }^{9}-21\right]}$ 
Figure 1: Pyrazole-containing pharmaceuticals and natural products (a) and $\lambda^{3}$-iodanes (b).

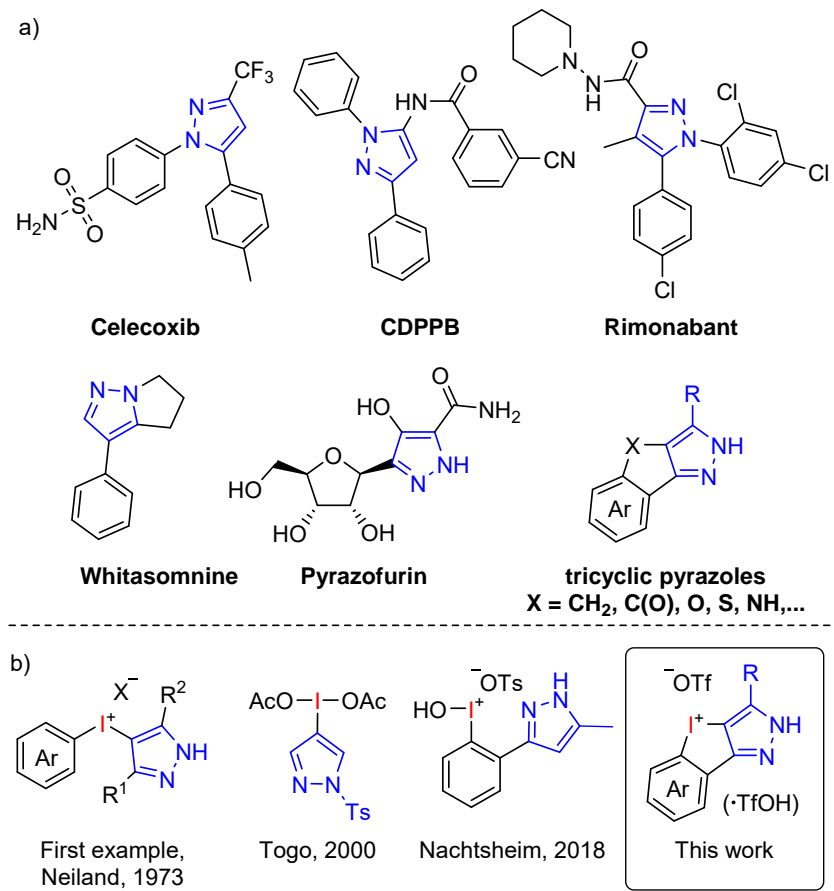

Due to the high relevance of this heterocycle, reactive synthetic intermediates already substituted by a pyrazole would allow the fast modification of a given target. Hypervalent iodine reagents are in general versatile building blocks and specific group transfer reagents, with diaryliodonium salts or alkynyl- $\lambda^{3}$-iodanes being prominent examples. ${ }^{[22-38]}$ Even though pyrazole-substituted iodanes and diaryliodonium salts are known (Scheme 1, c), ${ }^{[39-51]}$ selective applications as electrophilic group transfer reagents are still scarce. ${ }^{[52-54]}$

Our group is interested in the synthesis and reactivity of $N$-heterocyclic stabilized iodanes (NHIs) as well as their monovalent iodoarenes as pre-catalysts. ${ }^{[55-59]}$ Recently, we investigated several hydroxy(tosyloxy) species as oxidants, including $\mathrm{C}$ - and $\mathrm{N}$ bound pyrazole and indazole derivatives. ${ }^{[57,58]}$ Herein, we want to report the synthesis of cyclic, pyrazole-substituted iodolium salts (benzo[4,5]iodolo[3,2-c]pyrazol-4-ium (bis)triflates) and their versatile utilization as intermediates for pyrazole functionalization strategies as well as their application as potent halogen bonding $(\mathrm{XB})$ donors. 


\section{Results and Discussion}

We started our investigation with the oxidation of 5-methyl-pyrazole 1a (Scheme 1) using a slight excess of TfOH (1.1 equiv) in DCM. As expected, the intermediary $\mathrm{N}$ heterocyclic-stabilized iodane $\mathbf{2 a}$ was the only product formed after $2.5 \mathrm{~h}$. After an elongated reaction time ( $65 \mathrm{~h}$ ) formation of the desired product $3 \mathrm{3a}$ was observed and its structure was unambiguously confirmed via X-ray. After optimization (see SI for details) complete conversion towards the iodolopyrazolium bistriflate $\mathbf{3 a}$ was achieved using 2.0 equivalents of $\mathrm{TfOH}$ in $\mathrm{MeCN}$.

Isolated intermediate $\mathbf{2 a}$ showed no signs of cyclization in the absence of additional $\mathrm{TfOH}$ even after several days in MeCN, but readily cyclizes upon the addition of substoichiometric amounts of $\mathrm{TfOH}$ ( 0.5 equiv) in $16 \mathrm{~h}$.

Scheme 1: Oxidation of $1 \mathbf{a}$ and crystal structure of $3 \mathbf{a}^{\mathrm{a}}$

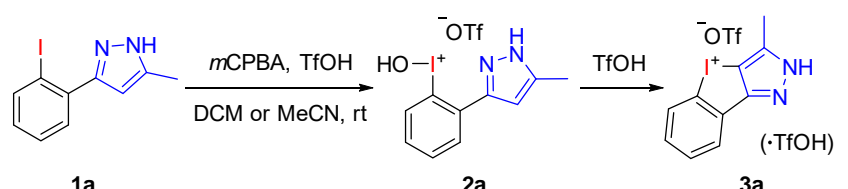

$1 a$

2a

$3 a$

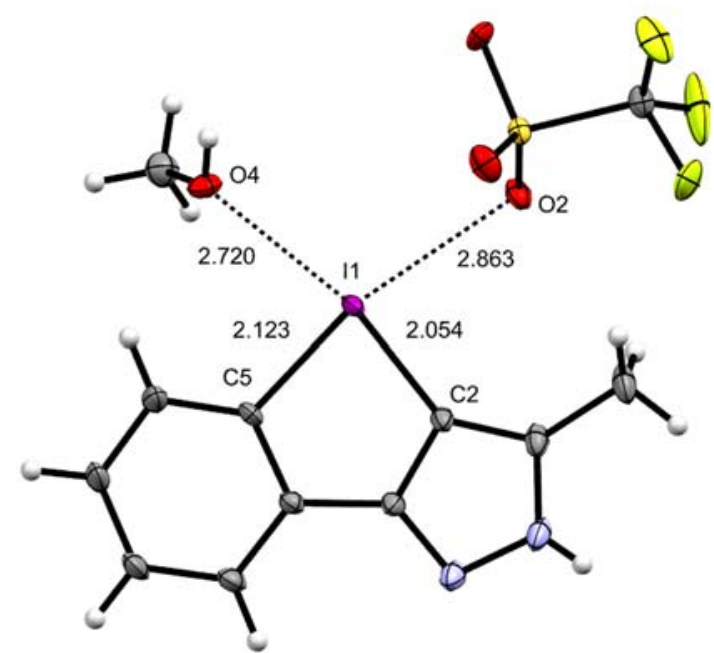

Oxidative cyclization of $\mathbf{1} \mathbf{a}$ to $\mathbf{3} \mathbf{a}$ and X-ray structure (ORTEP drawing) of $3 \mathbf{a}$ (CCDC 2011721) with coordination of $\mathrm{MeOH}$ and $\mathrm{TfO}^{-}$to the iodine. Selected bond lengths: I1-C5: $2.123 \AA$; I1-C2: $2.054 \AA$; I1-O2: $2.863 \AA$; I1-O4: $2.720 \AA$. Selected bond angles: C2-I1-C5: 81.52 ; C5-I1-O2A:

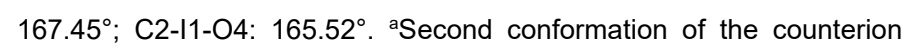
omitted for clarity.

With these optimized reaction conditions, the reaction scope was investigated on a $0.150 \mathrm{mmol}$ scale (Scheme 2). On this scale, 3a was obtained in 92\%. Likewise, the 3,5-dimethyl pyrazole $\mathbf{1} \mathbf{b}$ gave the cyclization product $\mathbf{3 b}$ in $88 \%$. Formation of $\mathbf{3 b} \mathbf{b i g h t}$ 
be the reason why pyrazole $\mathbf{1 b}$ showed a very low performance in our recently investigated $\alpha$-tosyloxylation using NHIs. ${ }^{[55]} \mathrm{Next}$, the alkyl side chain was varied. Pyrazoles with a $n$-butyl or a $t$-butyl group yielded 3c and $3 \mathbf{d}$ in $67-70 \%$. Since a potential low solubility of the intermediary formed NHIs in MeCN might have caused these diminished yields, we adapted the original procedure and used DCM as the solvent (Method B). With this slight adaption significantly better yields (81-84\%) were obtained. With an even bulkier adamantyl side chain only Method B was applicable giving $\mathbf{3 e}$ in $90 \%$ yield. The unsubstituted 3-(2-iodophenyl)-1H-pyrazole (1f) yielded $\mathbf{3 f}$ in $74 \%$. Trimethylsilyl and acetamido moieties were tolerated giving $\mathbf{3 g}$ and $\mathbf{3 h}$ in yields of $79-94 \%$ (Method B).

Scheme 2: Substrate Scope ${ }^{a}$

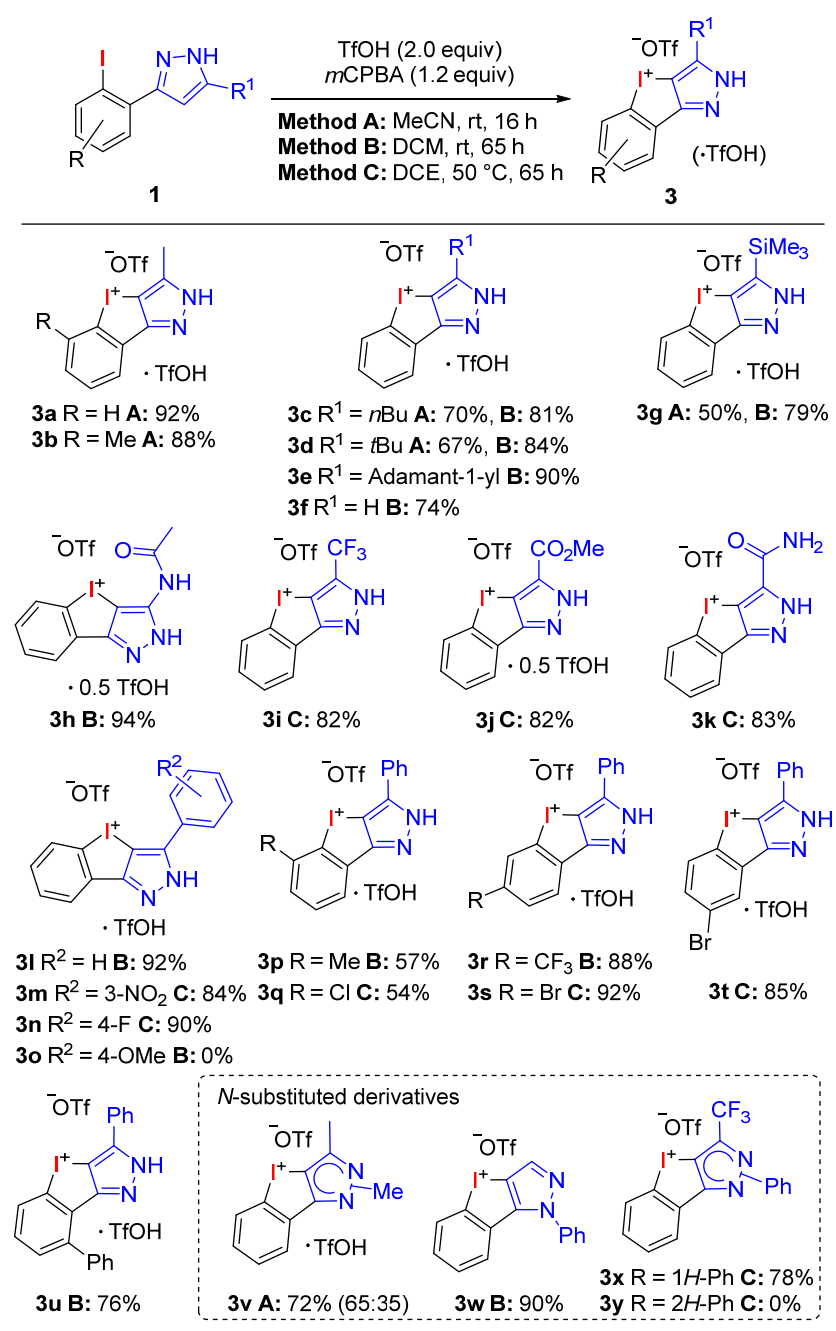

aReaction conditions: 1 (0.150 mmol), mCPBA (85\%, $36.8 \mathrm{mg}$, $0.180 \mathrm{mmol}, 1.2$ equiv) and $\mathrm{TfOH}(26.4 \mu \mathrm{L}, 0.300 \mathrm{mmol}, 2.0$ equiv) in the corresponding solvent $(1.5 \mathrm{~mL})$ for $16 \mathrm{~h}(\mathbf{A})$ or $65 \mathrm{~h}(\mathbf{B}, \mathbf{C})$ at room temperature $(\mathbf{A}, \mathbf{B})$ or $50^{\circ} \mathrm{C}(\mathbf{C})$. DCE: 1,2-dichloroethane. 
With a strong electron withdrawing $\mathrm{CF}_{3}$-group on the pyrazole core, harsher conditions were needed due to the higher electron deficiency of the intrinsically already electron poor $N$-heterocycle. Therefore, we adapted our initially optimized conditions again and performed the reaction at $50^{\circ} \mathrm{C}$. While the reaction in MeCN gave only a complex mixture, the cyclization was feasible in 1,2-dichloroethane (82\%). Interestingly, product 3i showed only one equivalent of the triflate counterion. Under the same conditions, further electron withdrawing groups such as a methyl ester (3j) or an amide (3k) were applicable (82-83\%).

While a thiophene group was not tolerated, the 3-phenyl derivative 3l was obtained in excellent yield (92\%). Substrates with electron withdrawing groups on the phenyl group $\left(\mathrm{NO}_{2}, \mathrm{~F}\right)$ gave the corresponding iodolium salts $3 \mathrm{~m}-\mathbf{n}$ in high yields (84-90\%), while strong electron donating methoxy groups are not tolerated under these conditions (30). Finally, different substituents on the iodophenyl-part were investigated. An orthomethyl or ortho-chloro moiety gave slightly diminished results, yielding $3 p$ in $57 \%$ and $3 q$ in $54 \%$, respectively. In contrast, substrates bearing trifluoromethyl, bromo or phenyl units in the 4-6 position performed well, furnishing the desired products $3 r-v$ in high to excellent yields (76-92\%).

Next, it was investigated whether $N$-substituted pyrazoles are also applicable under these reaction conditions. When a 58:42-mixture of $N$-methyl substituted pyrazole $\mathbf{1 v}$ was submitted to the reaction, the cyclized product $3 \mathbf{v}$ was obtained in $72 \%$ yield as a 65:35-mixture of isomers. Using a $N$-phenyl-substituted pyrazole $\mathbf{1 w}$, the corresponding product 3w was obtained in $90 \%$. Following this result, both $N$-phenyl substituted $\mathrm{CF}_{3}$-pyrazole isomers $\mathbf{1 x}-\mathbf{y}$ were tested. The $1 \mathrm{H}$-derivative $\mathbf{1 x}$ yielded the desired product $3 \mathbf{x}$ in $78 \%$, whereas the $2 \mathrm{H}$-derivative $1 \mathbf{y}$ gave no cyclization product, but only the stabilized hydroxy-NHI.

We also performed a gram-scale experiment $(5.00 \mathrm{mmol})$ using $\mathbf{1 l}$, giving the bistriflate $3 \mathbf{I}$ in $89 \%$. Recrystallization from $\mathrm{MeCN} / \mathrm{H}_{2} \mathrm{O}$ furnished the monotriflate $\mathbf{3} \mathbf{l}$ in $82 \%$ overall yield (Scheme 3, a). As the bis triflate salt formation was observed for several substrates throughout the substrate scope, simple recrystallization from aqueous solution - as indicated by the formation of the monotriflate 3l' - would be a convenient methodology for the generation of defined monotriflates. To test this, compounds $3 a-$ b and $\mathbf{3} \mathbf{f}$ were recrystallized from $\mathrm{H}_{2} \mathrm{O}$, fortunately yielding the iodolopyrazolium triflates 3a'-b' and 3f' in 72-95\% (Scheme 3, b). 
Scheme 3: Gram-scale experiment with $1 \mathrm{ll}(\mathrm{a})$ and removal of $\mathrm{TfOH}(\mathrm{b})$.

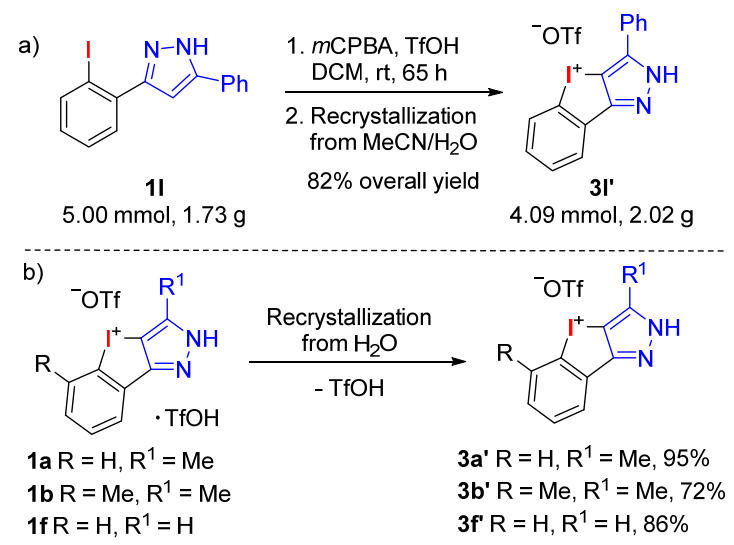

To demonstrate the applicability of these novel iodolopyrazolium triflates different derivatisations were investigated based on the 3-methyl and the 3-phenyl derivatives 3a' and 3l' (Scheme 4). Exchange of the counterion was easily achieved by deprotonation and subsequent treatment of the betaine with acetic acid, yielding the water-soluble acetate $\mathbf{3 a b}$ in $96 \%$. Counter ion exchange can be performed by treatment of a hot solution of the triflate derivative with an aqueous solution of either $\mathrm{KI}$ or $\mathrm{KBr}$. Thermolysis of the unpurified iodolopyrazolium salts resulted in regioselective ring opening at the pyrazole. While iodolopyrazolium iodides gave the diiodo compounds $\mathbf{4 a}$ and $\mathbf{4 b}$ in $58 \%$ and $78 \%$ yield over two steps, thermolysis of the 3-methyl iodolopyrazolium bromide yielded $\mathbf{5}$ in 79\%. Copper mediated transformations showed a different selectivity. In a three-component reaction with sodium azide and phenylacetylene, the 3-methyl species 3a' gave the pyrazolo[4,3c][1,2,3]triazolo[1,5-a]quinoline 6 in $22 \%$ yield. So far there is no other synthetic procedure available for this novel fused heterocycle. The copper-catalysed ring opening of 3l' with acetate followed by hydrolysis furnished the phenol $\mathbf{7}$ in $70 \%$ yield. Lastly, sulphur-iodine and selenium-iodine exchange reactions were conducted, yielding 3-phenyl-2H-benzo[4,5]thieno[3,2-c]pyrazole (8) in $63 \%$ and the seleno derivative 9 in 23\%. Hence this method gives an easy synthetic entrance towards benzoselenophenopyrazoles. ${ }^{[60,61]}$ 
Scheme 4: Derivatisations of $3 a^{\prime}$ and $3 l^{\prime} .^{a}$

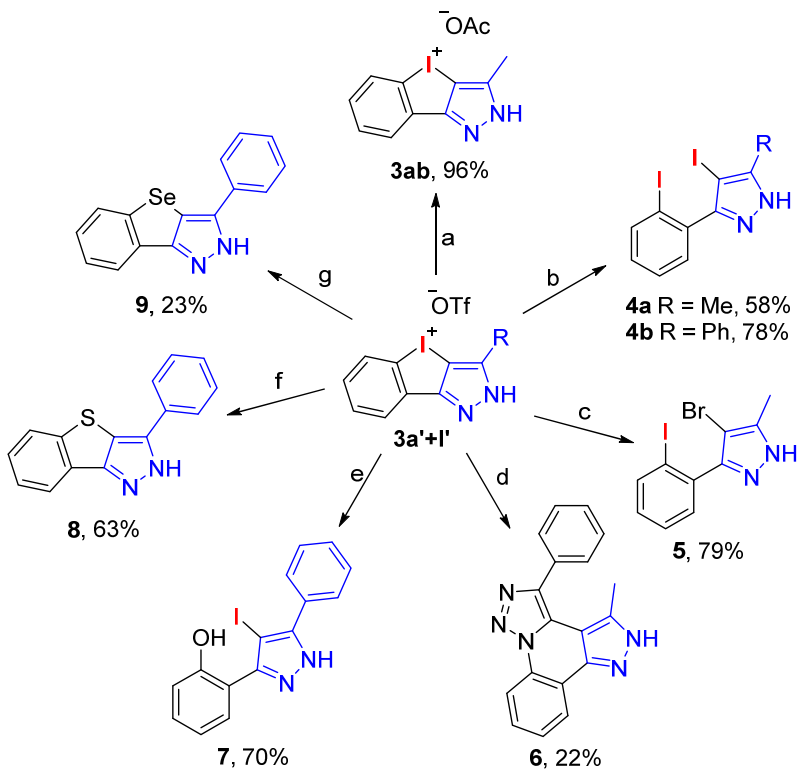

aReaction conditions: a) (i)1 $\mathrm{M} \mathrm{NaOH}$, hot $\mathrm{MeCN}, 5 \mathrm{~min}$, (ii) $\mathrm{AcOH}$, $\mathrm{H}_{2} \mathrm{O}, 5 \mathrm{~min}$; b) (i) $\mathrm{KI}, \mathrm{H}_{2} \mathrm{O}$, hot $\mathrm{EtOH}$, (ii) neat, $185-190{ }^{\circ} \mathrm{C}, 5 \mathrm{~min}$; c) (i) $\mathrm{KBr}, \mathrm{H}_{2} \mathrm{O}$, hot $\mathrm{EtOH}$, (ii) neat, $220^{\circ} \mathrm{C}, 5 \mathrm{~min}$; d) (i) $\mathrm{NaN}_{3}$, phenylacetylene, Cul, $\mathrm{NaHCO}_{3}, \mathrm{DMSO}$, argon, rt, $23 \mathrm{~h}$, (ii) air, $50^{\circ} \mathrm{C}, 22 \mathrm{~h}$; e) (i) $\mathrm{NaOAc}, \mathrm{CuSO}_{4} \cdot 5 \mathrm{H}_{2} \mathrm{O}, \mathrm{Ac}_{2} \mathrm{O}, \mathrm{AcOH}, 120^{\circ} \mathrm{C}$, $6 \mathrm{~h}$, (ii) $\mathrm{NaOH}, \mathrm{DCM}, \mathrm{MeOH}, 0.5 \mathrm{~h}$; f) $\mathrm{S}_{8}, \mathrm{Cs}_{2} \mathrm{CO}_{3}, \mathrm{DMSO}, 100^{\circ} \mathrm{C}$, $5 \mathrm{~h} ; \mathrm{g}) \mathrm{Se}, \mathrm{Cs}_{2} \mathrm{CO}_{3}, \mathrm{DMSO}, 80^{\circ} \mathrm{C}, 18 \mathrm{~h}$.

Inspired by the high functional group tolerance the synthesis of two iodolopyrazolium species 3z-za based on the 2'-iodo-substituted derivatives 1z-za of the pharmaceuticals Celecoxib and CDPPB (Scheme 5) was envisioned. Applying the established conditions for pyrazoles with electron-withdrawing substituents (Method C), 2'-iodo-Celecoxib $\mathbf{1 z}$ gave the desired product $\mathbf{3 z}$ in $89 \%$ yield on small scale and nearly quantitative yield on gram-scale (Scheme 5, a). On the other hand, similar to the acetamido derivative $1 \mathrm{~h}$, the CDPPB analogue $\mathbf{1 z a}$ readily reacted at room temperature (Method B) yielding the cyclized species $3 z a$ in $88 \%$ (Scheme $5, b$ ). 
Scheme 5: Oxidative cyclization of 2'-iodo-Celecoxib $1 z$ (a) and 2'-iodo-CDPPB 1za (b). ${ }^{\text {a }}$

a)

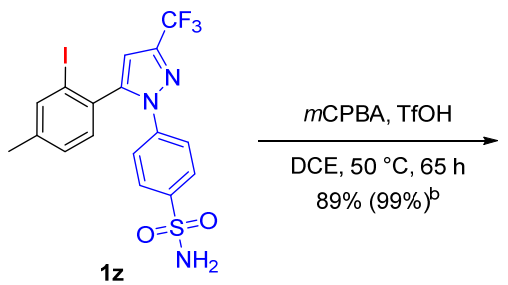

b)

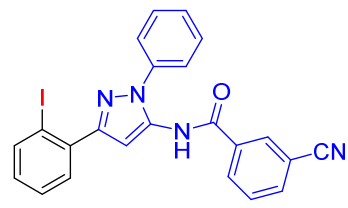

$1 z a$
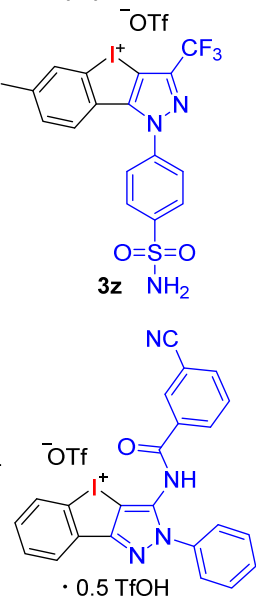

$3 z a$

aReaction conditions: 1 (0.150 mmol), mCPBA (85\%, $36.8 \mathrm{mg}$, $0.180 \mathrm{mmol}, 1.2$ equiv) and $\mathrm{TfOH}(26.4 \mu \mathrm{L}, 0.300 \mathrm{mmol}, 2.0$ equiv) in the corresponding solvent $(1.5 \mathrm{~mL}) .{ }^{\mathrm{b}} 2.00 \mathrm{mmol}$ scale.

Both, $\mathbf{3 z}$ as well as $\mathbf{3 z a}$, have a high potential as valuable building blocks for the synthesis of diversely substituted derivatives of these interesting biologically active compounds. Therefore, derivatisations towards highly functionalized Celecoxib analogues were further investigated (Scheme 6). Treatment of $\mathbf{3 z}$ with Cul/piperidine gave the diiodide 10 in $82 \%$ yield. Reactions with $O$ - and $N$-nucleophiles furnished the phenol 11 in $70 \%$ and the aniline 12 in $93 \%$.

Scheme 6: Cu-mediated derivatisations of $3 z$.
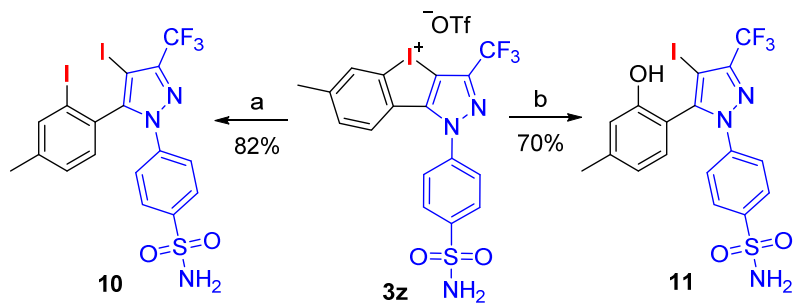

c $\mid 93 \%$

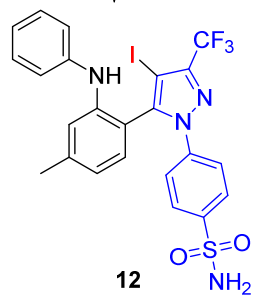

aReaction conditions: a) Cul, piperidine, $\mathrm{Na}_{2} \mathrm{CO}_{3}, \mathrm{DCM}, 40^{\circ} \mathrm{C}$, $1 \mathrm{~h}$; b) (i) $\mathrm{NaOAc}, \mathrm{CuSO}_{4} \cdot 5 \mathrm{H}_{2} \mathrm{O}, \mathrm{Ac}_{2} \mathrm{O}, \mathrm{AcOH}, 120^{\circ} \mathrm{C}, 5 \mathrm{~h}$, (ii) $\left.\mathrm{NaOH}, \mathrm{H}_{2} \mathrm{O} ; \mathrm{c}\right) \mathrm{Cu}(\mathrm{OAc})_{2} \bullet \mathrm{H}_{2} \mathrm{O}$, aniline, $\mathrm{Na}_{2} \mathrm{CO}_{3}, i \mathrm{PrOH}, 40^{\circ} \mathrm{C}$, $18 \mathrm{~h}$. 
Finally, due to their intrinsic electron deficiency caused by the fused pyrazole moiety the performance of iodolopyrazolium triflates in XB-based halide abstractions was investigated. In the solvolysis of benzhydryl halides with acetonitrile as the benchmark reaction iodolium salts of type $\mathbf{1 5}$ showed the highest activity outperforming previous reported bidentate XB-donors. ${ }^{[62]}$ As the unsubstituted iodolopyrazolium triflate $\mathbf{3 f}$ ' would not be suitable because of the $\mathrm{NH}$-moiety, $\mathrm{N}$-phenyl derivative $3 \mathrm{w}$ was chosen instead (Scheme 7). Initially, the formation of acetamide 14 via the easier activated benzhydryl bromide $13 a$ was investigated. $3 w$ showed a high reactivity forming the desired product in $79 \%$ yield after $4 \mathrm{~h}$, whereas with iodolium triflate 15 61\% was observed. Intrigued by this finding, we tested this transformation with the significantly less reactive benzhydryl chloride $\mathbf{1 3 b}$ and were pleased to observe a high reactivity for $3 w$ with this substrate as well, yielding 14 in $59 \%$ after only $8 \mathrm{~h}$. In comparison, the use of 15 as the model XB-donor gave acetamide 14 in only $19 \%$ under the same conditions, which was in good accordance with previously reported results. ${ }^{[62]}$ Increasing the reaction time to $16 \mathrm{~h}$ finally lead to the formation of $14 \mathrm{in} 77 \%$ yield. This experiment implies that $\mathbf{3} w$ is the most active $\mathrm{XB}$-donor for this transformation reported to date.

Scheme 7: XB-based halide abstraction. ${ }^{a}$

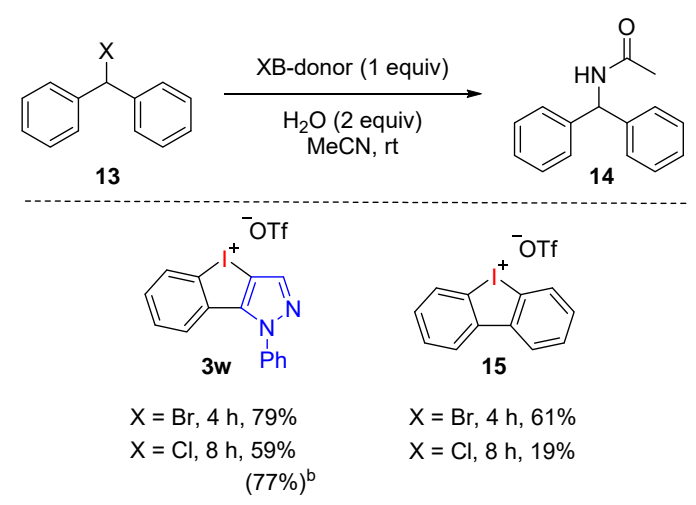

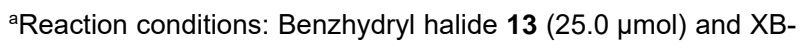
donor $3 \mathrm{w}$ or $15(25.0 \mu \mathrm{mol})$ were stirred in wet $\mathrm{MeCN}(2.5 \mathrm{~mL})$ at room temperature $\left(25^{\circ} \mathrm{C}\right.$ ). Yields (average of two separated runs) were determined via ${ }^{1} \mathrm{H}-\mathrm{NMR}$ using dimethyl malonate as the internal standard. ${ }^{\mathrm{b}} 16 \mathrm{~h}$ reaction time.

\section{Summary}

In conclusion, we investigated the direct oxidative cyclization of 3-(2-iodophenyl)-1Hpyrazoles to novel iodolopyrazolium (bis)triflates via in situ formed $N$-heterocyclicstabilized hydroxy- $\lambda^{3}$-iodanes. The reaction exhibits a broad functional group tolerance 
as a wide variety of substrates containing alkyl-, aryl-, silyl-, trifluoromethyl-, ester-, amide- and halide substituents are well tolerated, both, at the pyrazole as well as on the (iodo)aryl core. With further derivatizations, in particular highly site-selective ringopenings but also heterocycle formation, the wide application of these $\mathrm{N}$-heterocyclic iodolium salts was demonstrated. This was successfully applied towards efficient functionalizations of the COX-2 inhibitor Celecoxib into valuable and potentially biologically active building blocks. Finally, the potential of a well-chosen iodolopyrazolium (bis)triflate as XB-donor was investigated in the solvolysis of benzhydryl halides. High reactivity in the halide abstraction was observed, outperforming previously reported XB-donors for this benchmark reaction.

Deeper investigations towards the formation and reactivity of the iodolopyrazolium triflates, in particular as XB-donors, and the synthesis of further $\mathrm{N}$-heterocyclecontaining iodolium derivatives in a broader sense are under current investigation in our laboratory.

\section{Experimental Section}

Detailed experimental procedures, complete optimization and characterization data including the corresponding ${ }^{1} \mathrm{H}$ and ${ }^{13} \mathrm{C}$ NMR spectra for all new compounds and the X-ray data for $\mathbf{3 a}$ can be found in the supporting information.

\section{Acknowledgement}

Funding by the Fonds der Chemischen Industrie (PhD scholarship to $A B)$ is gratefully acknowledged.

\section{References}

[1] S. Fustero, M. Sánchez-Roselló, P. Barrio, A. Simón-Fuentes, Chem. Rev. 2011, 111, 6984.

[2] A. Ansari, A. Ali, M. Asif, S. Shamsuzzaman, New J. Chem. 2017, 41, 16.

[3] K. Karrouchi, S. Radi, Y. Ramli, J. Taoufik, Y. N. Mabkhot, F. A. Al-Aizari, M.'h. Ansar, Molecules 2018, 23.

[4] T. D. Penning, J. J. Talley, S. R. Bertenshaw, J. S. Carter, P. W. Collins, S. Docter, M. J. Graneto, L. F. Lee, J. W. Malecha, J. M. Miyashiro et al., J. Med. Chem. 1997, 40, 1347. 
[5] C. W. Lindsley, D. D. Wisnoski, W. H. Leister, J. A. O'brien, W. Lemaire, D. L. Williams, M. Burno, C. Sur, G. G. Kinney, D. J. Pettibone et al., J. Med. Chem. 2004, 47, 5825.

[6] L. F. van Gaal, A. M. Rissanen, A. J. Scheen, O. Ziegler, S. Rössner, The Lancet 2005, 365, 1389.

[7] H.-B. Schröter, D. Neumann, A. R. Katritzky, F. J. Swinbourne, Tetrahedron 1966, 22, 2895.

[8] G. E. Gutowski, M. J. Sweeney, D. C. DeLong, R. L. Hamill, K. Gerzon, R. W. Dyke, Ann. N. Y. Acad. Sci. 1975, 255, 544.

[9] M. A. Shareef, K. Sirisha, I. Khan, I. B. Sayeed, S. S. Jadav, G. Ramu, C. G. Kumar, A. Kamal, B. N. Babu, MedChemComm 2019, 10, 806.

[10]M. Irshad, Q. Ali, F. Iram, S. A. Ahmad, M. Saleem, M. Saadia, M. Batool, A. Kanwal, S. Tabassum, Russ. J. Gen. Chem. 2019, 89, 1734.

[11]Z. Hou, S. Oishi, Y. Suzuki, T. Kure, I. Nakanishi, A. Hirasawa, G. Tsujimoto, H. Ohno, N. Fujii, Org. Biomol. Chem. 2013, 11, 3288.

[12]H. Minegishi, S. Fukashiro, H. S. Ban, H. Nakamura, ACS Med. Chem. Lett. 2013, 4, 297.

[13]M. D. Rosen, C. R. Woods, S. D. Goldberg, M. D. Hack, A. D. Bounds, Y. Yang, P. C. Wagaman, V. K. Phuong, A. P. Ameriks, T. D. Barrett et al., Bioorg. Med. Chem. Lett. 2009, 19, 6548.

[14]J. Dinges, D. H. Albert, L. D. Arnold, K. L. Ashworth, I. Akritopoulou-Zanze, P. F. Bousquet, J. J. Bouska, G. A. Cunha, S. K. Davidsen, G. J. Diaz et al., J. Med. Chem. 2007, 50, 2011.

[15] J. Dinges, I. Akritopoulou-Zanze, L. D. Arnold, T. Barlozzari, P. F. Bousquet, G.

A. Cunha, A. M. Ericsson, N. Iwasaki, M. R. Michaelides, N. Ogawa et al., Bioorg. Med. Chem. Lett. 2006, 16, 4371.

[16]K. Murata, H. Kumagai, T. Kawashima, K. Tamitsu, M. Irie, H. Nakajima, S. Suzu, M. Shibuya, S. Kamihira, T. Nosaka et al., J. Biol. Chem. 2003, 278, 32892.

[17]D. A. Nugiel, A. Vidwans, A.-M. Etzkorn, K. A. Rossi, P. A. Benfield, C. R. Burton, S. Cox, D. Doleniak, S. P. Seitz, J. Med. Chem. 2002, 45, 5224.

[18]D. A. Nugiel, A. M. Etzkorn, A. Vidwans, P. A. Benfield, M. Boisclair, C. R. Burton, S. Cox, P. M. Czerniak, D. Doleniak, S. P. Seitz, J. Med. Chem. 2001, 44, 1334. 
[19]J. G. Jurcak, M. Barrague, T. A. Gellespy, M. L. Edwards, K. Y. Musick, P. M. Weintraub, Y. Du, R. M. Dharanipragada, A. A. Parkar (Aventis Pharmaceuticals), WO2005026175A1, 2005.

[20]L. D. Arnold, Y. Xu, T. Barlozzari (BASF Aktiengesellschaft), US6451834B1, 2002.

[21]K. J. Doyle, P. Rafferty, R. W. Steele, D. J. Wilkins, L. D. Arnold, M. Hockley, A. M. Ericsson, N. Iwasaki, N. Ogawa (BASF Aktiengesellschaft), US6462036B1, 2002.

[22] V. V. Grushin, Chem. Soc. Rev. 2000, 29, 315.

[23]N. Chatterjee, A. Goswami, Eur. J. Org. Chem. 2017, 2017, 3023.

[24]P. J. Stang, V. V. Zhdankin, Chem. Rev. 1996, 96, 1123.

[25]T. Wirth, Synthesis 1999, 1271.

[26]R. M. Moriarty, J. Org. Chem. 2005, 70, 2893.

[27] T. Wirth, Angew. Chem. Int. Ed. 2005, 44, 3656.

[28]M. S. Yusubov, V. V. Zhdankin, Curr. Org. Synth. 2012, 9, 247.

[29] G. Maertens, C. L'Homme, S. Canesi, Front. Chem. 2014, 2, 115.

[30]J. Charpentier, N. Früh, A. Togni, Chem. Rev. 2015, 115, 650.

[31]A. Yoshimura, V. V. Zhdankin, Chem. Rev. 2016, 116, 3328.

[32]X. Wang, A. Studer, Acc. Chem. Res. 2017, 50, 1712.

[33]D. P. Hari, P. Caramenti, J. Waser, Acc. Chem. Res. 2018, 51, 3212.

[34]A. Boelke, P. Finkbeiner, B. J. Nachtsheim, Beilstein J. Org. Chem. 2018, 14, 1263.

[35] G. Grelier, B. Darses, P. Dauban, Beilstein J. Org. Chem. 2018, 14, 1508.

[36]M. Ghosh, A. Rajkiewicz, M. Kalek, Synthesis 2019, 51, 359.

[37] V. V. Zhdankin, Hypervalent Iodine Chemistry, John Wiley \& Sons Ltd, Chichester, UK, 2013.

[38] T. Wirth (Ed.), Hypervalent lodine Chemistry, Topics in Current Chemistry, Springer International Publishing, Cham, 2016.

[39]B. Y. Karele, S. V. Kalnin', I. P. Grinberga, O. Y. Neiland, Chem. Heterocycl. Compd. 1973, 9, 226.

[40] G. Maas, M. Regitz, U. Moll, R. Rahm, F. Krebs, R. Hector, P. J. Stang, C. M.

Crittell, B. L. Williamson, Tetrahedron 1992, 48, 3527.

[41]P. J. Stang, P. Murch, Tetrahedron Lett. 1997, 38, 8793.

[42] Togo, Nabana, Yamaguchi, J. Org. Chem. 2000, 65, 8391. 
[43]T. Nabana, H. Togo, J. Org. Chem. 2002, 67, 4362.

[44]M. Bielawski, J. Malmgren, L. M. Pardo, Y. Wikmark, B. Olofsson, ChemistryOpen 2014, 3, 19.

[45]Z. Gonda, Z. Novák, Chem. Eur. J. 2015, 21, 16801.

[46]F. Xie, Z. Zhang, X. Yu, G. Tang, X. Li, Angew. Chem. Int. Ed. 2015, 54, 7405.

[47]Y. Wu, S. Izquierdo, P. Vidossich, A. Lledós, A. Shafir, Angew. Chem. Int. Ed. 2016, 55, 7152.

[48]K. Ishida, H. Togo, K. Moriyama, Chem. Asian. J. 2016, 11, 3583.

[49]N. Lu, L. Huang, L. Xie, J. Cheng, Eur. J. Org. Chem. 2018, 2018, 3437.

[50]T. Dohi, T. Hayashi, S. Ueda, T. Shoji, K. Komiyama, H. Takeuchi, Y. Kita, Tetrahedron 2019, 75, 3617.

[51]Q. Y. Toh, A. McNally, S. Vera, N. Erdmann, M. J. Gaunt, J. Am. Chem. Soc. 2013, 135, 3772.

[52]I. Sokolovs, D. Lubriks, E. Suna, J. Am. Chem. Soc. 2014, 136, 6920.

[53]W. R. Roush, D. Duckertt, A. Monas-Tyrskyi (The Scripps Research Institute), WO2019217421A1, 2019.

[54]F. C. Sousa E Silva, N. T. Van, S. E. Wengryniuk, J. Am. Chem. Soc. 2020, 142, 64.

[55]A. Boelke, B. J. Nachtsheim, Adv. Synth. Catal. 2020, 362, 184.

[56]A. H. Abazid, B. J. Nachtsheim, Angew. Chem. Int. Ed. 2020, 59, 1479.

[57]A. Boelke, Y. A. Vlasenko, M. S. Yusubov, B. J. Nachtsheim, P. S. Postnikov, Beilstein J. Org. Chem. 2019, 15, 2311.

[58]A. Boelke, E. Lork, B. J. Nachtsheim, Chem. Eur. J. 2018, 24, 18653.

[59] C. Hempel, C. Maichle-Mössmer, M. A. Pericàs, B. J. Nachtsheim, Adv. Synth. Catal. 2017, 359, 2931.

[60]R. Lisiak, J. Młochowski, Synthetic Communications 2009, 39, 4271.

[61]M. Elsherbini, W. S. Hamama, H. H. Zoorob, J. Heterocyclic Chem. 2018, 55, 1645.

[62]F. Heinen, E. Engelage, A. Dreger, R. Weiss, S. M. Huber, Angew. Chem. Int. Ed. 2018, 57, 3830. 